\title{
Is raloxifene associated with lower risk of mortality in postmenopausal women with vertebral fractures after vertebroplasty?: a hospital-based analysis
}

\author{
Fu-Mei Su', Ying-Chou Chen ${ }^{1 *}$, Tien-Tsai Cheng ${ }^{1}$, Wei-Che Lin ${ }^{2}$ and Chun-Chung Lui ${ }^{2}$
}

\begin{abstract}
Background: Osteoporotic fractures are associated with mortality in postmenopausal woman. Whether raloxifen treatment after vertebroplasty can reduce mortality is unclear in this group. To compare the effect of raloxifene and no osteoporosis treatment on the risk of mortality after vertebroplasty, we designed this study.
\end{abstract}

Methods: This was a retrospective study (January 2001 to December 2007). Follow-up for each participant was calculated as the time from inclusion in the study to the time of death, or to December $31^{\text {st }}, 2013$, whichever occurred first. All of the patients underwent baseline bone density studies, and age and body mass index $\left(\mathrm{kg} / \mathrm{m}^{2}\right)$ were recorded. All associated medical diseases such as diabetes, hypertension, and liver and renal disease were recorded.

Results: One hundred and forty-nine patients with vertebral fractures were enrolled, of whom 51 used raloxifene and 98 patients did not receive any anti-osteoporotic therapy. At the end of the follow-up period, 62 patients had died and 87 were still alive. The treated patients had a lower mortality rate than those who did not receive treatment $(P=0.001, \mathrm{HR}=3.845,95 \% \mathrm{Cl} 1.884-7.845)$. The most common cause of mortality was sepsis, and those who received raloxifene had a lower rate of sepsis compared to those who did not receive treatment $(P<0.001)$.

Conclusions: Effective treatment with raloxifene may had a lower mortality rate in patients with postmenopausal osteoporosis-related vertebral fractures after vertebroplasty.

\section{Background}

Raloxifene is a selective estrogen-receptor modulator that has been shown to prevent bone loss. In postmenopausal women with osteoporosis, treatment with raloxifene has been shown to decrease markers of bone turnover by 30 to $40 \%$ after one year of usage, and increase bone density at several scanning sites by 2 to $3 \%$ after three years of use [1-3]. Raloxifene has also been shown to decrease the incidence of vertebral fractures by 30 to $50 \%$, depending on dosage, but not the incidence of hip fractures or other non-vertebral fractures [1].

Osteoporotic fractures of the spine are common with aging, and the lifetime risk of a symptomatic vertebral

\footnotetext{
* Correspondence: r820713@ms13.hinet.net

'Department of Rheumatology, Kaohsiung Chang Gung Memorial Hospital, Chang Gung University College of Medicine, 123 Ta-Pei RoadNiao-Sung District, Kaohsiung 833, Taiwan

Full list of author information is available at the end of the article
}

compression fracture has been estimated to be $18 \%$ for women and $11 \%$ for men [4]. In addition, painful, clinically apparent vertebral fractures have been reported to increase overall mortality by up to $15 \%[4,5]$. Furthermore, some individuals will become disabled by severe pain that lasts for longer than 2 to 3 months.

Data from studies on raloxifene used to reduce the risk of fractures can provide a way to test the hypothesis that treating osteoporosis reduces the risk of death. If treating osteoporosis does have a positive impact on mortality, there would be several important potential implications for managing skeletal health specifically, and for health care for women in general. Therefore, in this study, we investigated whether raloxifene treatment affects mortality rates in postmenopausal woman with vertebral fractures. 


\section{Methods}

This was a retrospective review of osteoporosis patients with vertebral fractures. The Institutional Review Board of Kaohsiung Chang Gang Memorial Hospital approved this study, and it was conducted in accordance with the Declaration of Helsinki and the International Conference on Harmonization of Good Clinical Practice Guidelines. According to Taiwan law, no additional informed consent was required, and patient information was anonymized and de-identified before data analysis.

The inclusion criteria were postmenopausal women with a radiological diagnosis of a vertebral fracture followed by a vertebral augmentation procedure for a painful vertebral compression fracture, and failure of conservative pain management. All patients were examined with magnetic resonance imaging, and we obtained the electronic medical records of all patients who underwent vertebral augmentation procedures. Patients were excluded if their fracture had a pathological source or had been caused by more than minimal trauma. We choose those with raloxifen treatment $(60 \mathrm{mg} / \mathrm{d}$ after vertebroplasy) and those without treatment with any anti-osteoporotic therapy for comparison.

Follow-up for each participant was calculated as the time from inclusion in the study to the time of death, or to December $31^{\text {st }}, 2013$, whichever occurred first. All of the patients underwent baseline bone density studies, and age and body mass index $\left(\mathrm{kg} / \mathrm{m}^{2}\right)$ were recorded. All associated medical diseases such as diabetes, hypertension, and liver and renal disease were recorded.

\section{Statistical analysis}

Statistical analysis was performed using SPSS software, version 21.0 (SPSS, Chicago, IL, USA). Kaplan-Meyer analysis with the log rank test was performed for different groups. Comparisons between independent means were analyzed using the independent t test, and relationships between categorical variables were evaluated by the chi-square test. Cox regression analysis was used to adjust for potential confounding factors. A $P$ value of less than 0.05 was considered to be statistically significant.

\section{Results}

One hundred and forty-nine patients with vertebral fractures were enrolled in this study, of whom 51 used raloxifene and 98 did not receive anti-osteoporotic therapy. All were grade 3 by semiquantitative grading scale for vertebral fracture and $\mathrm{T}$ score $<-2.5$ with bone densitometry. The mean age at the index day was $74.24 \pm$ 7.62 years in the raloxifene group and $72.52 \pm 9.70$ years in those who did not receive treatment. The mean followup period was $7.08 \pm 3.67$ years.
At the end of the follow-up period, 62 patients had died and 87 were still alive. The patients who received raloxifene survived for longer than those who did not receive treatment $(P=0.04)$. There were no significant differences in body mass index, number of vertebral fractural, previous hip fracture,or underlying diseases including diabetes, hypertension, cardiovascular disease, pulmonary disease, liver disease, or neurological diseases (Table 1).

Raloxifene therapy had a significant effect on survival according to Kaplan-Meier curves (Fig. 1). After adjusting for potential confounding factors such as diabetes, hypertension, cardiovascular disease, pulmonary disease, liver disease and neurological diseases, the patients treated with raloxifene still had a lower mortality rate than those who did not receive treatment $(P=0.001, \mathrm{HR}=3.845$, $95 \%$ CI 1.884-7.845) (Table 2). The most common cause of mortality overall was sepsis, however the rate of sepsis was significantly lower in the raloxifene group compared to the no treatment group $(P<0.001)$ (Fig. 2$)$.

\section{Discussion}

Raloxifene is a non-steroidal benzothiophene analog that has been shown to inhibit the growth of estrogenreceptor-dependent dimethylbenzanthracene-induced mammary tumors and reduce the occurrence of nitrosomethylurea-induced mammary tumors in rats. It is classified as a selective estrogen-receptor modulator on the basis of studies in which it prevented bone

Table 1 Baseline characteristics of the study patients

\begin{tabular}{|c|c|c|c|c|}
\hline & & Raloxifene & No treatment & $P$ value \\
\hline Age (years) & & $74.24 \pm 7.62$ & $72.52 \pm 9.70$ & 0.238 \\
\hline Body mass index $\left(\mathrm{kg} / \mathrm{m}^{2}\right)$ & & $22.80 \pm 4.82$ & $24.12 \pm 4.85$ & 0.116 \\
\hline Survival years & & $8.06 \pm 2.63$ & $6.11 \pm 4.33$ & 0.004 \\
\hline Fracture no (spine) & & $1.83 \pm 1.07$ & $1.48 \pm 1.48$ & 0.158 \\
\hline \multirow[t]{2}{*}{ Previous hip fracture } & No & $46(90.2 \%)$ & $88(89.8 \%)$ & 0.592 \\
\hline & Yes & $5(9.8 \%)$ & $10(10.2 \%)$ & \\
\hline \multirow[t]{2}{*}{ Diabetes } & No & $38(74.5 \%)$ & $73(74.5 \%)$ & 0.581 \\
\hline & Yes & $13(25.5 \%)$ & $25(25.5 \%)$ & \\
\hline \multirow[t]{2}{*}{ Hypertension } & No & $25(49.0 \%)$ & $46(46.9 \%)$ & 0.864 \\
\hline & Yes & $26(51.0 \%)$ & $52(53.1 \%)$ & \\
\hline \multirow[t]{2}{*}{ Neurological disease } & No & $50(98.0 \%)$ & $97(99.0 \%)$ & 1 \\
\hline & Yes & $1(2.0 \%)$ & $1(1.0 \%)$ & \\
\hline \multirow[t]{2}{*}{ Pulmonary disease } & No & 49(96.1\%) & $92(93.9 \%)$ & 0.716 \\
\hline & Yes & $2(3.9 \%)$ & $6(6.1 \%)$ & \\
\hline \multirow[t]{2}{*}{ Cardiovascular disease } & No & 49(96.1\%) & $93(94.9 \%)$ & 1 \\
\hline & Yes & $2(3.9 \%)$ & $5(5.1 \%)$ & \\
\hline \multirow[t]{2}{*}{ Liver disease } & No & $47(92.2 \%)$ & $91(92.9 \%)$ & 1 \\
\hline & Yes & $4(7.8 \%)$ & $7(7.1 \%)$ & \\
\hline
\end{tabular}




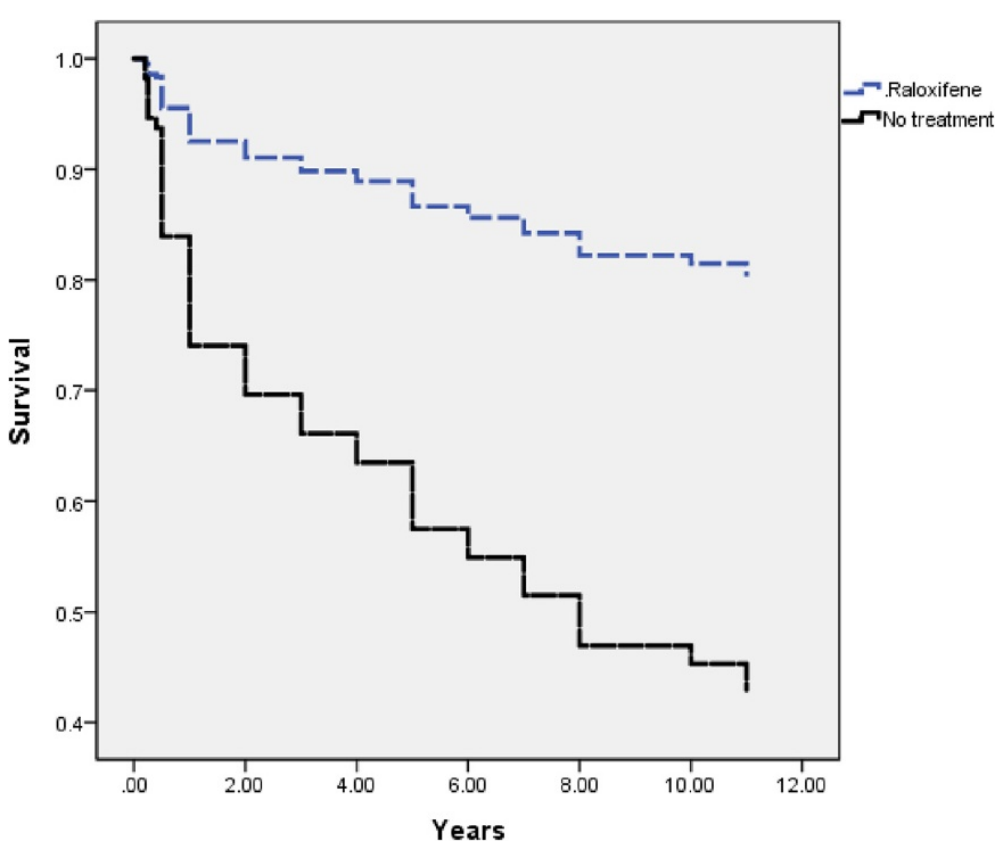

Fig. 1 Kaplan-Meier survival curves for raloxifen therapy (dashed line) and no treatment (solid line)

loss and lowered serum cholesterol concentrations without stimulating the endometrium [6-9].

Theoretically, effective prevention and treatment strategies can be implemented once a high-risk individual has been identified. It is essential that evidence-based recommendations be incorporated into clinical practice [10]. Despite the availability of effective treatment in the Taiwan health care system, effective osteoporosis interventions are not optimal for women with a history of osteoporotic vertebral fractures. This is consistent with a population-based study, in which only one in five patients with a fragility fracture received treatment for osteoporosis within the following year [11]. Other studies have also reported insufficient levels of treatment, with the probability of being treated being inversely related to age and lower among older women [12-14].

Decisions regarding the treatment of postmenopausal osteoporosis should be based on the patient's risk for fractures, drug efficacy and the side effects of these drugs. Individuals with a fragility vertebral fracture should always be treated when not contraindicated, because the risk of subsequent vertebral fractures is very high [15]. Based on the scientific evidence, raloxifene appears to be a good option.

Established osteoporosis has been associated with a high mortality rate after adjusting for age and comorbidities [16, 17], and prevalent vertebral deformities have been reported to predict increased mortality and
Table 2 Effect of raloxifene on mortality after adjusting for variables

\begin{tabular}{llccr}
\hline & Regression coefficient & SE & $P$ value & HR \\
\hline Age (years) & .029 & .018 & .105 & 1.029 \\
Body mass index $\left(\mathrm{kg} / \mathrm{m}^{2}\right)$ & -.032 & .030 & .289 & .968 \\
Diabetes & -.567 & .294 & .054 & .567 \\
Hypertension & -.159 & .273 & .560 & .853 \\
Neurological disease & .235 & 1.057 & .824 & 1.265 \\
Liver disease & -.554 & .497 & .265 & .574 \\
Cardiovascular disease & .676 & .730 & .355 & 1.966 \\
Pulmonary disease & .214 & .604 & .723 & 1.239 \\
Raloxifene use & 1.347 & .364 & .000 & 3.845 \\
\hline
\end{tabular}

Abbreviations: SE: standard error; HR: hazard ratio

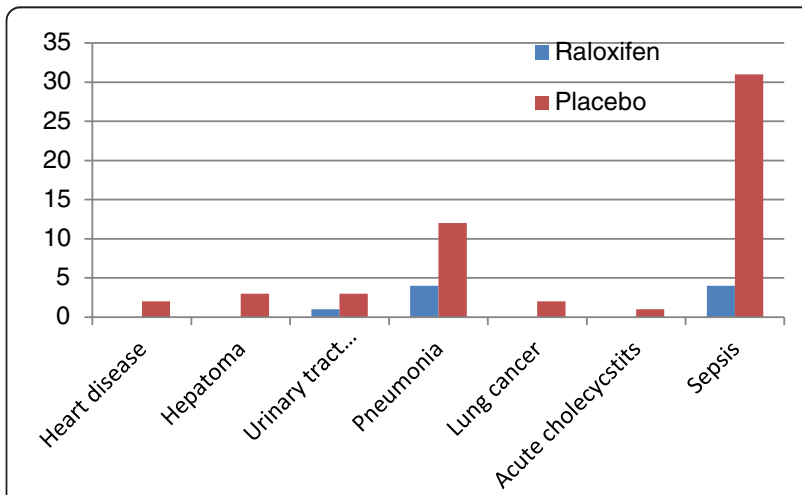

Fig. 2 Comparison of the of the death between raloxifene and placebo group 
fracture rates in both men and women [18-23]. Treatment for osteoporosis with established methods for vertebral and non-vertebral fractures has been reported to reduce mortality in older, frailer individuals with osteoporosis who are at a high risk of fractures [24-26].

In clinical practice, some patients with vertebral fractures do not receive medical therapy after vertebroplasty, and this may contribute to subsequent vertebral fractures and increased mortality [27]. Our results show that raloxifene therapy can reduce mortality, underscoring the importance of educating patients with osteoporosis about the value of raloxifene therapy. We also noted a decreased incidence of sepsis after raloxifene treatment compared to those who did not receive treatment.

It is not clear how raloxifene reduce risk of death due to infection [28]. Estrogen receptor ligands have been shown to reduce bacteremia and mortality in experimental models of infection [29]. Because vertebral fractures have been associated with increased pulmonary causes of mortality [30], so vertebral fracture might be associated with shallow respiration and increased risk of pneumonia and associated sepsis. So raloxifen reduces the risk of sepsis by decrease vertebral fracture.

A possible reason for this may be because raloxifene therapy decreases the frequency of subsequent fractures, thereby improving mobility and decreasing the infection rate.

There are several limitations to his study. First, the number of vertebral fractures was probably underestimated, given the inherent difficulty of diagnosing them. For instance, only about a third of cases of all vertebral deformities detected on radiographs receive medical attention, and less than $10 \%$ require admission to hospital. Second, the sample size was small. Third, there was a lack of complete bone mineral density data after osteoporosis treatment. However, in this single-center cohort, we collected as much data as possible, and this study included only fragility fractures in patients older than 50 years without a secondary etiology. Thus, the patients' fractures were due to osteoporosis.

This study also has a number of strengths. First, it was a long-term cohort study with a mean follow-up period of 7 years, which made it possible to gather sufficient follow-up data on survival. In addition, baseline magnetic resonance imaging scans were taken for each participant, all of whom had clinically diagnosed vertebral fractures. Thus, we were able to exclude other secondary causes of vertebral fractures such as cancer or pyogenic infections.

\section{Conclusions}

In conclusion, our results showed that raloxifene therapy can reduce the mortality rate of postmenopausal women with osteoporotic vertebral fractures. After adjusting for comorbidities, the patients who received raloxifene therapy still had a lower mortality rate. Thus, optimal management with raloxifene may reduce the risk of death.

\section{Competing interests}

The authors declare that they have no competing interests.

\section{Authors' contributions}

FMS was responsible for the study design, clinical assessment, analysis, communication of data and drafting the manuscript. YCC was responsible for the study design and the generation, analysis, communication of data and critical revision of important intellectual content. $\mathrm{BH}$ was responsible for the study design, clinical assessment, analysis, communication of data and critical revision of important intellectual content. TTC was responsible for the statistical design, data analysis and critical revision of important intellectual content. WCL was responsible for study design, analysis of data and critical revision of important intellectual content. CCL was responsible for the study design, served as the clinical coordinator, and performed data analysis, critical revision of important intellectual content. All authors read and approved the final manuscript.

\section{Acknowledgements}

We thank Kaohsiung Chang Gung Memorial Hospital for providing the related data.

\section{Author details}

${ }^{1}$ Department of Rheumatology, Kaohsiung Chang Gung Memorial Hospital, Chang Gung University College of Medicine, 123 Ta-Pei RoadNiao-Sung District, Kaohsiung 833, Taiwan. ${ }^{2}$ Department of Radiology, Kaohsiung Chang Gung Memorial Hospital, Chang Gung University College of Medicine, Kaohsiung 833, Taiwan.

Received: 19 February 2015 Accepted: 10 August 2015 Published online: 19 August 2015

\section{References}

1. Ettinger B, Black DM, Mitlak BH, Knickerbocker RK, Nickelsen T, Genant HK, et al. Reduction of vertebral fracture risk in postmenopausal women with osteoporosis treated with raloxifene: results from a 3-year randomized clinical trial. Multiple Outcomes of Raloxifene Evaluation (MORE) Investigators. Jama. 1999;282(7):637-45.

2. Lufkin EG, Whitaker MD, Nickelsen T, Argueta R, Caplan RH, Knickerbocker RK, et al. Treatment of established postmenopausal osteoporosis with raloxifene: a randomized trial. J Bone Miner Res Off J Am Soc Bone Miner Res. 1998;13(11):1747-54.

3. Delmas PD, Bjarnason NH, Mitlak BH, Ravoux AC, Shah AS, Huster WJ, et al. Effects of raloxifene on bone mineral density, serum cholesterol concentrations, and uterine endometrium in postmenopausal women. $\mathrm{N}$ Engl J Med. 1997;337(23):1641-7.

4. Cooper C, Atkinson EJ, Jacobsen SJ, O'Fallon WM, Melton 3rd LJ. Population-based study of survival after osteoporotic fractures. Am J Epidemiol. 1993;137(9):1001-5.

5. Hasserius R, Karlsson MK, Jonsson B, Redlund-Johnell I, Johnell O. Long-term morbidity and mortality after a clinically diagnosed vertebral fracture in the elderly-a 12- and 22-year follow-up of 257 patients. Calcif Tissue Int. 2005;76(4):235-42.

6. Turner $\mathrm{CH}$, Sato M, Bryant HU. Raloxifene preserves bone strength and bone mass in ovariectomized rats. Endocrinology. 1994;135(5):2001-5.

7. Black $\amalg$, Sato M, Rowley ER, Magee DE, Bekele A, Williams DC, et al. Raloxifene (LY139481 HCl) prevents bone loss and reduces serum cholesterol without causing uterine hypertrophy in ovariectomized rats. J Clin Invest. 1994;93(1):63-9.

8. Clemens JA, Bennett DR, Black LJ, Jones CD. Effects of a new antiestrogen, keoxifene (LY156758), on growth of carcinogen-induced mammary tumors and on LH and prolactin levels. Life Sci. 1983;32(25):2869-75.

9. Anzano MA, Peer CW, Smith JM, Mullen LT, Shrader MW, Logsdon DL, et al. Chemoprevention of mammary carcinogenesis in the rat: combined use of raloxifene and 9-cis-retinoic acid. J Natl Cancer Inst. 1996;88(2):123-5. 
10. Brown JP, Josse RG. clinical practice guidelines for the diagnosis and management of osteoporosis in Canada. CMAJ : Canadian Medical Association journal = journal de I'Association medicale canadienne 2002. 2002;167(10 Suppl):S1-34.

11. Siris ES, Miller PD, Barrett-Connor E, Faulkner KG, Wehren LE, Abbott TA, et al. Identification and fracture outcomes of undiagnosed low bone mineral density in postmenopausal women: results from the National Osteoporosis Risk Assessment. Jama. 2001;286(22):2815-22.

12. Hajcsar EE, Hawker G, Bogoch ER. Investigation and treatment of osteoporosis in patients with fragility fractures. CMAJ : Canadian Medical Association journal = journal de l'Association medicale canadienne. 2000;163(7):819-22.

13. Kamel HK, Hussain MS, Tariq S, Perry HM, Morley JE. Failure to diagnose and treat osteoporosis in elderly patients hospitalized with hip fracture. Am J Med. 2000;109(4):326-8.

14. Freedman KB, Kaplan FS, Bilker WB, Strom BL, Lowe RA. Treatment of osteoporosis: are physicians missing an opportunity? J Bone Joint Surg Am. 2000;82-A(8):1063-70.

15. Lindsay R, Silverman SL, Cooper C, Hanley DA, Barton I, Broy SB, et al. Risk of new vertebral fracture in the year following a fracture. Jama. 2001;285(3):320-3

16. Shiraki M, Kuroda T, Tanaka S. Established osteoporosis associated with high mortality after adjustment for age and co-mobidities in postmenopausal Japanese women. Intern Med. 2011:50(5):397-404.

17. Ismail AA, O'Neill TW, Cooper C, Finn JD, Bhalla AK, Cannata JB, et al. Mortality associated with vertebral deformity in men and women: results from the European Prospective Osteoporosis Study (EPOS). Osteoporos Int. 1998:8(3):291-7.

18. Hasserius R, Karlsson MK, Nilsson BE, Redlund-Johnell I, Johnell O. Prevalent vertebral deformities predict increased mortality and increased fracture rate in both men and women: a 10-year population-based study of 598 individuals from the Swedish cohort in the European Vertebral Osteoporosis Study. Osteoporos Int. 2003;14(1):61-8

19. Jalava T, Sarna S, Pylkkanen L, Mawer B, Kanis JA, Selby P, et al. Association between vertebral fracture and increased mortality in osteoporotic patients. J Bone Miner Res Off J Am Soc Bone Miner Res. 2003;18(7):1254-60.

20. Naves M, Diaz-Lopez JB, Gomez C, Rodriguez-Rebollar A, Rodriguez-Garcia $M$, Cannata-Andia JB. The effect of vertebral fracture as a risk factor for osteoporotic fracture and mortality in a Spanish population. Osteoporos Int. 2003; 14(6):520-4

21. Nguyen ND, Ahlborg HG, Center JR, Eisman JA, Nguyen TV. Residual lifetime risk of fractures in women and men. J Bone Miner Res Off J Am Soc Bone Miner Res. 2007;22(6):781-8.

22. Puisto $\mathrm{V}$, Rissanen $\mathrm{H}$, Heliovaara $\mathrm{M}$, Impivaara $\mathrm{O}$, Jalanko $\mathrm{T}$, Kroger $\mathrm{H}$, et al. Vertebral fracture and cause-specific mortality: a prospective population study of 3,210 men and 3,730 women with 30 years of follow-up. Eur Spine J. 2011;20(12):2181-6.

23. Lau E, Ong K, Kurtz S, Schmier J, Edidin A. Mortality following the diagnosis of a vertebral compression fracture in the Medicare population. J Bone Joint Surg Am. 2008;90(7):1479-86.

24. Bolland MJ, Grey AB, Gamble GD, Reid IR. Effect of osteoporosis treatment on mortality: a meta-analysis. J Clin Endocrinol Metab. 2010;95(3):1174-81.

25. Center JR, Bliuc D, Nguyen ND, Nguyen TV, Eisman JA. Osteoporosis medication and reduced mortality risk in elderly women and men. J Clin Endocrinol Metab. 2011;96(4):1006-14.

26. Grey A, Bolland MJ. The effect of treatments for osteoporosis on mortality. Osteoporos Int. 2013;24(1):1-6.

27. Huntjens KM, Kosar S, van Geel TA, Geusens PP, Willems P, Kessels A, et al. Risk of subsequent fracture and mortality within 5 years after a nonvertebral fracture. Osteoporos Int. 2010;21(12):2075-82.

28. Grady D, Cauley JA, Stock JL, Cox DA, Mitlak BH, Song J, et al. Effect of Raloxifene on all-cause mortality. Am J Med. 2010;123(5):469. e461-467.

29. Cristofaro PA, Opal SM, Palardy JE, Parejo NA, Jhung J, Keith Jr JC, et al. WAY-202196, a selective estrogen receptor-beta agonist, protects against death in experimental septic shock. Crit Care Med. 2006;34(8):2188-93.

30. Kado DM, Browner WS, Palermo L, Nevitt MC, Genant HK, Cummings SR. Vertebral fractures and mortality in older women: a prospective study. Study of Osteoporotic Fractures Research Group. Arch Intern Med. 1999;159(11):1215-20.

\section{Submit your next manuscript to BioMed Central and take full advantage of:}

- Convenient online submission

- Thorough peer review

- No space constraints or color figure charges

- Immediate publication on acceptance

- Inclusion in PubMed, CAS, Scopus and Google Scholar

- Research which is freely available for redistribution 